\title{
RELAÇÃO DAS FAMÍLIAS COM A ESCOLARIDADE E SUCESSO ESCOLAR: COMPÁRAÇÃO ENTRE FAMÍLIAS DE ORIGEM CABO-VERDIANA, ORIGEM INDIANA E AUTÓCTONES
}

\author{
FAMILY-SCHOOL RELATIONSHIP AND SCHOOL SUCCESS: COMPARISON \\ BETWEEN FAMILIES OF CAPE-VERDIAN ORIGIN, INDIAN ORIGIN AND \\ NATIVES
}

\author{
Teresa SEABRA ${ }^{1}$
}

RESUMO: A explicação para a desigualdade dos desempenhos escolares dada pelos profissionais da educação vem frequentemente associada à amplitude do apoio familiar à escolarização dos descendentes. Com o intuito de explorarmos esta relação analisam-se resultados de parte de um inquérito por questionário aplicado junto de crianças do $5^{\circ}$ e $6^{\circ}$ ano de escolaridade, onde foi possível identificar a trajectória escolar de cada aluno e as representações e práticas dos seus progenitores na relação com a escola. Trata-se de um total de 837 alunos distribuídos por 8 escolas dos concelhos de Lisboa e Loures, com diferentes origens nacionais. Compara-se a informação para os alunos autóctones, para os que têm origem cabo-verdiana e os que têm origem indiana. Concluímos que o apoio familiar à escolaridade (índice construído com base na ida às reuniões escolares, no controlo que exercem sobre os trabalhos de casa, no apoio prestado nas dificuldades e, ainda, no diálogo sobre a vida escolar) contribui para o desempenho escolar e que as duas variáveis variam numa relação directa. Contudo, esse apoio não constitui, de modo algum, uma condição suficiente ao êxito ou fracasso escolares, dado não ser pertinente concluir pelo efeito decisivo das práticas de apoio familiar à escolaridade sobre os resultados que os alunos obtêm na escola. Verificou-se, ainda, existir uma relação mais forte com os resultados obtidos quando se trata dos alunos de origem cabo-verdiana e mais frágil com são os de origem indiana.

PALAVRAS-CHAVE: Família-escola. Sucesso Escolar. Ensino básico.

ABSTRACT: The explanation for the inequality of school performances given by education professionals is often associated with the amplitude of the family support to the offspring's education. In order to explore this relationship we analyze the results of part of a survey questionnaire applied to children in the 5th and 6th grade, where it was possible to identify the trajectory school of each student and the representations and practices of their parents in relation with the school. This is a total of 837 students spread over 8 schools in the municipalities of Lisbon and Loures with different national origins. We compared the information to indigenous students, for those who have Cape Verdean origin and those of Indian origin. We conclude that family support for education (index built on the way to school meetings, the control they exert over their homework, the dialogue about school life and the support given by the families to the difficulties) contributes to school performance and that the two variables vary in a direct relationship. But this is not, in any way, a sufficient condition for success or failure in school as it is not unreasonable to conclude the decisive

1 Instituto Universitário de Lisboa (ISCTE-IUL), Departamento de Sociologia. Lisboa - Portugal. E-mail: teresa.seabra@iscte.pt. 
effect of the practices of family support for education about the results students get in school. There was also a stronger relationship with the results when it comes to the students of Cape Verdean origin and more fragile with those of Indian origin.

KEYWORKS: Family-school. School success. Compulsory school.

\section{Introdução}

A investigação no domínio da relação das famílias com a escola desenvolveu-se apenas nos últimos trinta anos, mas o debate em torno dos papéis de cada instituição educativa tem a idade da própria escola. A polémica fez-se sentir nos finais do século XVIII, em que se debateu a supremacia de uma instituição relativamente à outra: enquanto para uns devia ser restringido ao máximo possível o papel educativo das famílias, por serem o contexto em que vigoram os preconceitos, as tradições e as irracionalidades podendo a acção da escola estender-se, inclusive, à regeneração das próprias famílias, por influência dos descendentes junto dos seus progenitores (MONTANDON, 1994) ${ }^{2}$, para outros o papel de ambas devia ser claramente distinto e o sistema público não podia afectar os direitos dos pais, sendo a defesa destes direitos um dos argumentos utilizados para restringir a educação pública à instrução. ${ }^{3}$

De facto, historicamente, a escola não aparece como um prolongamento da acção da família, mas como uma instituição com finalidades específicas, jamais desempenháveis pelas famílias. Contra o que era dominante nas sociedades tradicionais (como o particularismo e a fragmentação cultural), a nova ordem social reclamava práticas universalistas e a criação e sustentação de uma cultura comum. ${ }^{4}$

Como afirmam Kellerhals e Montandon (1991), com o advento da universalização da escola, a família passa de instância primordial e exclusiva no processo de socialização/educação das crianças e jovens a instância que acumula as funções de educadora com as de gestora da acção dos outros contextos educativos (primeiramente a escola e o grupo

\footnotetext{
${ }^{2}$ Há ecos de vozes que defendiam que as crianças sendo pertença da nação e não dos seus pais (não sendo estes mais que seus depositários) deveriam ser retiradas às famílias pelo período de alguns anos para que pudessem ter uma educação comum sustentada pelo Estado. O "espírito" da época pode sintetizar-se nesta afirmação de Danton: "tudo se retrai na educação doméstica e tudo se engrandece na educação comum" (LELIÉVE, 1990 apud MONTANDON, 1994).

${ }^{3}$ Ideia defendida nomeadamente por Condorcet no seu Plano de Instrução Pública (CONDORCET, 1790 apud MONTANDON, 1994, p.150).

${ }^{4}$ Como sabemos, a escola foi decisiva tanto na edificação dos modernos Estados-nação como na expansão e consolidação do modo industrial de produção.
} 
de pares e mais recentemente os media e as múltiplas instâncias educativas de ocupação dos tempos livres), e é, ainda, co-responsável no fracasso ou êxito escolares ${ }^{5}$.

Dubet (1997, p.27) defende que a polémica em torno das interrelações escola-família esteve "adormecida" até aos anos sessenta do século passado, por estarem os papéis de ambas as instâncias educativas suficientemente separados, cabendo à escola e aos professores instruir e dar o sentido universalista à educação das novas gerações: “[...] este sistema não dava lugar aos pais e a autoridade dos mestres não era contestada."

À medida que a escola vai alargando a sua base social de recrutamento e faz permanecer nela, por períodos progressivamente mais longos, as crianças e jovens, intensificam-se as clivagens entre os modelos de socialização das duas instâncias acrescendo, concomitantemente, a dificuldade de comunicação entre elas.

A correspondência estrutural entre a especificidade cultural de certos grupos sociais (a classe média em ascensão) e a cultura escolar contribui para a existência de relações tensas entre as famílias com diferente perfil social: a escola acusa de alheamento as famílias socialmente mais desfavorecidas e critica as famílias com estatuto social mais elevado de excesso de interferência na vida escolar.

$\mathrm{Na}$ explicação do insucesso escolar é frequentemente evocado, especialmente pelos docentes, o desinteresse ou indiferença das famílias em relação à escola, nomeadamente, o reduzido apoio prestado à escolaridade dos filhos e a falta de ambições escolares. No entanto, toda a investigação tem revelado de modo consistente que as famílias dos meios sociais mais desfavorecidos não são demissionárias. Pelo contrário, alguns autores têm salientado a existência de uma lógica obsessiva na relação com a escola: uns consideram que estas famílias inculcam com eficácia a crença na escola e só podem ser consideradas demissionárias na medida em que "não querem jogar aos professores em casa" (SINGLY, 1997, p.45) e outros salientam que o que é percebido pelos professores como abandono é confiança na escola e no metier do professor - a sua distância deve ser entendida como uma não intromissão correspondente ao desejo de que a escola não se intrometa na sua vida pessoal e familiar (DUBET, 1997). Outros, ainda, constataram que só os membros de uma parte da aristocracia, do "lumpen" proletariado (vivem de ocupações pontuais, sem qualquer planificação no tempo) e dos grupos de pequenos proprietários que contam passar o negócio

${ }^{5}$ A actual proliferação de fileiras em concorrência e uma forte hierarquização das escolas, requer ainda que as famílias se tornem seus consumidores informados de modo a serem "especialistas" para orientar as crianças no labirinto das formações e para antecipar as orientações. 
aos filhos não investem na escola e esta aparece como um elemento não significativo nos projectos de futuro (BERTHELOT, 1983).

As pesquisas que têm procedido a uma análise mais fina da relação dos grupos sociais mais desfavorecidos com a escola, têm identificado variações no perfil das classes populares que se relacionam com a intensidade de investimento na escolaridade:

i) as famílias populares urbanas têm ambições mais elevadas do que as rurais e manifestam sentimentos de revolta e desespero face ao insucesso escolar (HENRIOT-VAN, 1990) ii) as que vivem a história escolar dos filhos dentro da desorientação - a incerteza, a resignação e o sentimento de não dominarem nada em relação à escola (têm maior desvantagem económica e menos recursos escolares) e as que têm uma esperança calculada e vigilante e esforçam-se por assegurar em casa uma continuidade com o trabalho escolar (famílias mais novas, mais urbanas, economicamente mais estáveis e mais qualificadas) (QUEIROZ, 1991).

Em suma, porque o destino social dos descendentes passou a ser parcialmente exterior à família, isso não significa que ela não se interesse por esse destino. Pelo contrário, redobra a sua atenção no sentido de controlar o destino escolar que lhe escapa em grande parte. Como salientam Ferhat e Terrail (2005), a massificação escolar intensificou o investimento de todas as famílias: das que passaram a ter acesso à escola e das que já dela faziam parte, adoptando estratégias de diferenciação e de perpetuação de uma situação de supremacia no campo escolar - estes autores revelam dados disponíveis em relação à sociedade francesa demonstrativos deste progressivo aumento do investimento familiar.

Em Portugal, este investimento na escolaridade tem-se feito igualmente sentir (BENAVENTE et al., 1987; DON, 1987; SANTIAGO, 1996; DIOGO, 1998; SEABRA, 1999; VIEIRA, 2003; DIOGO, 2008; SEABRA, 2010) e não têm sido menos complexos os processos de diferenciação entre escolas acompanhados, frequentemente, pela intensificação da segregação social dos públicos escolares (SEBASTIÃO, 2009; DIOGO, 2012).

O presente artigo retoma dados recolhidos no contexto da tese de doutoramento da autora (SEABRA, 2010) explorando-os com o intuito de comparar diferentes dinâmicas familiares de acompanhamento da escolaridade e sua eventual relação com os resultados escolares obtidos pelos educandos. A pesquisa teve como principal objectivo comparar as trajectórias escolares de alunos autóctones, alunos de origem cabo-verdiana e alunos de origem indiana e as diferentes condições e processos familiares e escolares vivenciados por estes diferentes grupos de alunos. A eleição destes grupos teve por base a indicação da estatística nacional que dizia tratar-se de alunos com um perfil de desempenho escolar muito diferenciado. 
A informação resulta da aplicação de um inquérito por questionário a 829 alunos do $5^{\circ}$ e 6 anos de escolaridade distribuídos por oito escolas localizadas nos concelhos de Lisboa e de Loures (Área metropolitana de Lisboa) em 2003 e de um conjunto de 11 entrevistas realizadas a pais destas crianças (cinco progenitoras de origem cabo-verdiana e seis progenitores de origem indiana).

As famílias foram seleccionadas tendo em conta a diversificação dos seus perfis sociais. No seu conjunto, tinham um tempo de residência em Portugal que variava entre um mínimo de 14 e um máximo de 32 anos. A fixação em Portugal é ligeiramente mais recente para as famílias de origem indiana, que fazem o seu regresso de Moçambique no início da década de oitenta, enquanto as de origem cabo-verdiana chegaram, quase todas, na década anterior, na maior parte dos casos, provenientes de países para onde já tinham anteriormente emigrado, os próprios ou os seus ascendentes e por razões essencialmente económicas. A lembrança dos primeiros tempos de vida em Portugal evoca mais ou menos dificuldades, não conforme a origem étnico-nacional, mas de acordo com o período de chegada ao país e/ou a condição económica de partida. Os apoios recebidos foram dados por outros imigrantes (alojamento e redes de interconhecimento) ou por instituições ou pessoas singulares portuguesas, sobretudo de cariz religioso (católicas).

A Tabela 1 sintetiza as condições de vida das famílias no momento das entrevistas quanto às qualificações e à situação socio-profissional. Os níveis de escolaridade atingidos pelos progenitores são intermédios (entre o $4^{\circ}$ e o $9^{\circ}$ ano), todas mães de origem caboverdiana são activas, enquanto as de origem indiana não desempenham actividade profissional, excepto a Shetal (F8) que trabalha na sua própria loja (e flexibiliza um pouco os horários) e a Radica (F10) que, ocasionalmente, faz trabalhos domésticos de limpeza para compensar as situações em que o marido está desempregado. Os dois empresários caboverdianos têm a sua própria empresa há poucos anos, depois de terem trabalhado no sector como empregados, durante bastante tempo.

Tabela 1: Perfil escolar e socio-profissional das famílias entrevistadas (momento da entrevista)

\begin{tabular}{|c|c|c|c|c|c|}
\hline \multirow{2}{*}{$\begin{array}{l}\text { Família } \\
\text { (entrevistado) }\end{array}$} & \multicolumn{2}{|c|}{ Grau de escolaridade } & \multicolumn{2}{|c|}{ Profissão } & \multirow{2}{*}{$\begin{array}{l}\text { Categoria socio- } \\
\text { profissional familiar }\end{array}$} \\
\hline & Mãe & Pai & Mãe & Pai & \\
\hline F1 (Luísa) & Licenciatura & $9^{\circ}$ & $\begin{array}{l}\text { Engenheira } \\
\text { civil }\end{array}$ & $\begin{array}{l}\text { Construtor } \\
\text { civil }\end{array}$ & $\begin{array}{l}\text { Empresários, } \\
\text { dirigentes e } \\
\text { profissionais liberáis }\end{array}$ \\
\hline F2 (Maria) & $9^{\circ}$ & $4^{\circ}$ & $\begin{array}{l}\text { Auxiliar } \\
\text { creche }\end{array}$ & $?$ & $\begin{array}{l}\text { Empregados } \\
\text { executantes }\end{array}$ \\
\hline F3 (Rosa) & $10^{\circ}$ & $4^{\circ}$ & $\begin{array}{l}\text { Auxiliar } \quad \mathrm{J} . \\
\text { Infância }\end{array}$ & $\begin{array}{l}\text { Carpinteiro } \\
\text { (conta }\end{array}$ & $\begin{array}{l}\text { Empresários, } \\
\text { dirigentes }\end{array}$ \\
\hline
\end{tabular}




\begin{tabular}{|c|c|c|c|c|c|}
\hline & & & & própria) & profissionais liberáis \\
\hline F4 (Débora) & $6^{\circ}$ & $4^{\circ}$ & Cozinheira & $\begin{array}{l}\text { Empregado } \\
\text { fabril }\end{array}$ & $\begin{array}{l}\text { Empregados } \\
\text { executantes }\end{array}$ \\
\hline F5 (Ana) & S/ grau & $9^{\circ}$ & $\begin{array}{l}\text { Empregada } \\
\text { limpezas }\end{array}$ & $?$ & $\begin{array}{l}\text { Empregados } \\
\text { executantes }\end{array}$ \\
\hline F6 (Pradip) & Licenciatura & Licenciatura & 1 & $\begin{array}{l}\text { Dentista } \\
\text { (conta } \\
\text { própria) }\end{array}$ & $\begin{array}{l}\text { Empresários, } \\
\text { dirigentes } \\
\text { profissionais liberáis }\end{array}$ \\
\hline F7 (Carima) & $6^{\circ}$ & $12^{\circ}$ & - & $\begin{array}{l}\text { Vendedor } \\
\text { (conta } \\
\text { própria) }\end{array}$ & $\begin{array}{l}\text { Trabalhadores } \\
\text { independents }\end{array}$ \\
\hline F8 (Shetal) & $6^{\circ}$ & $4^{\circ}$ & $\begin{array}{l}\text { Vendedora } \\
\text { (conta } \\
\text { própria) }\end{array}$ & $\begin{array}{l}\text { Empregado } \\
\text { de armazém }\end{array}$ & $\begin{array}{l}\text { Trabalhadores } \\
\text { independentes } \\
\text { pluriactivos }\end{array}$ \\
\hline F9 (Júlia) & S/ grau & $4^{\circ}$ & $\begin{array}{l}\text { Vendedora } \\
\text { (conta } \\
\text { própria) }\end{array}$ & $\begin{array}{l}\text { Vendedor } \\
\text { (conta } \\
\text { própria) }\end{array}$ & $\begin{array}{l}\text { Trabalhadores } \\
\text { independents }\end{array}$ \\
\hline F9 (Radica) & $6^{\circ}$ & $4^{\circ}$ & $\begin{array}{l}\text { Empregada } \\
\text { limpeza }\end{array}$ & $\begin{array}{l}\text { Vendedor } \\
\text { (conta de } \\
\text { outrem) }\end{array}$ & $\begin{array}{l}\text { Empregados } \\
\text { executantes }\end{array}$ \\
\hline F10 (Priti) & $5^{\circ}$ & $4^{\circ}$ & - & Empregado & Operários industriais \\
\hline
\end{tabular}

Fonte: Elaboração própria.

Os agregados domésticos incluem, tendencialmente, um elevado número de filhos (entre 3 e 6 filhos) e as situações de monoparentalidade são mais frequentes entre as famílias de origem cabo-verdiana, onde recaem, exclusivamente, os casos de divórcio ou separação do marido.

Que similitudes e diferenças se detectam nos modelos educativos das famílias com diferente origem nacional? Que objectivos perseguem as famílias na educação dos seus filhos? Serão diferentes as relações que estabelecem com a escolaridade dos seus descendentes? Que importância atribuem à escolarização destes? Que aspirações lhes revelam? O que fazem no acompanhamento dessa escolaridade?

Ainda antes de procurar responder a estas questões, fomos indagar qual a trajetória escolar destes alunos, controlando o efeito das condições sociais das suas famílias.

\section{Trajetórias escolares}

As trajectórias escolares destes alunos, apesar de ainda se encontrarem numa fase inicial da sua escolarização, são bastante marcadas pelas reprovações (Tabela 2): 39\% já reprovaram pelo menos uma vez ao longo da escolaridade, quase todos $(25 \%)$ ainda no $1^{\circ}$ ciclo.

Em consonância com as conclusões de toda a investigação produzida pela sociologia da educação, as raparigas obtêm melhores resultados no global dos alunos e em todos os 
subgrupos considerados. A distância entre a percentagem de rapazes e de raparigas que nunca reprovou é, em média, de $10 \%$, mas atinge os $18 \%$ quando se trata dos alunos com origem cabo-verdiana e quase desaparece quando se trata dos alunos com ascendência indiana (2\%).

Comparando o desempenho escolar dos alunos descendentes de indianos e de caboverdianos, constata-se a supremacia dos resultados obtidos pelos primeiros, que ultrapassam, inclusive, os dos alunos autóctones; a distância entre os dois grupos em análise ronda os 30\%, atendendo a que nunca reprovaram $73 \%$ e $44 \%$ dos alunos com ascendência indiana e caboverdiana, respectivamente. Importa destacar que estes últimos alunos são o único grupo em que a maioria já reprovou ao longo da sua (ainda curta) trajectória escolar e que esta repetência foi múltipla em $25 \%$ dos casos.

Tabela 2: Reprovações ao longo da trajetória escolar dos alunos

\begin{tabular}{|c|c|c|c|c|c|c|c|c|c|c|c|c|}
\hline \multirow[b]{2}{*}{ sexo } & \multicolumn{3}{|c|}{ Todos os alunos } & \multicolumn{3}{|c|}{ Autóctones } & \multicolumn{3}{|c|}{$\begin{array}{l}\text { Origem cabo- } \\
\text { verdiana }\end{array}$} & \multicolumn{3}{|c|}{ Origem indiana } \\
\hline & $\mathrm{F}$ & $\mathrm{M}$ & Total & $\mathrm{F}$ & $\mathrm{M}$ & Total & $\mathrm{F}$ & $\mathrm{M}$ & Total & $\mathrm{F}$ & $\mathrm{M}$ & Total \\
\hline 0 & 66.2 & 57.2 & 61.4 & 66.7 & 57.5 & 61.7 & 52.7 & 34.5 & 43.6 & 74.5 & 72.4 & 73.4 \\
\hline 1 & 20.5 & 23.9 & 22.3 & 17.4 & 22.6 & 20.2 & 29.1 & 34.5 & 31.8 & 17.6 & 15.5 & 16.5 \\
\hline $2 \mathrm{ou}+$ & 13.3 & 18.9 & 16.3 & 16.0 & 19.8 & 18.1 & 18.2 & 30.9 & 24.5 & 7.8 & 12.1 & 10.1 \\
\hline$n^{\circ}$ & 390 & 439 & 829 & 213 & 252 & 465 & 55 & 55 & 110 & 51 & 58 & 109 \\
\hline
\end{tabular}

Fonte: Elaboração própria.

\section{Relação das famílias com a escola}

\section{Práticas familiares de apoio à escolaridade}

A investigação revelou, corroborando todas as anteriores pesquisas, que as famílias se implicam significativamente na escolaridade: a grande maioria vai regularmente às reuniões escolares para as quais são convocadas, controla usualmente o cumprimento dos trabalhos de casa (TPC), dá ou cria condições para que seja dado apoio em situação de dificuldades escolares e conversa regularmente com os filhos sobre a escolaridade (Tabela 3).

Tabela 3: Práticas familiares de apoio à escolaridade

\begin{tabular}{lccc}
\hline \hline & Autóctones & $\begin{array}{c}\text { Origem cabo- } \\
\text { verdiana }\end{array}$ & Origem indiana \\
\hline Presença nas reuniões (todas ou parte) & 92.5 & 88.2 & 89.7 \\
Controlo sobre a realização dos TPC & 89.7 & 88.1 & 91.7 \\
Apoio nas dificuldades & 85.0 & 73.6 & 89.0
\end{tabular}


Fonte: Elaboração própria.

74.2

80.0

74.1

Na comparação entre os contextos familiares de origem cabo-verdiana e os de origem indiana, encontramos diferenciações: os alunos que vivem nas primeiras famílias, frequentam menos a educação pré-escolar, têm muito menos apoio nas dificuldades escolares, são menos controlados quanto à realização dos trabalhos de casa, os seus pais vão um pouco menos às reuniões convocadas pela escola e, em contrapartida, é mais frequente conversarem sobre as ocorrências escolares.

Dada a diversidade de perfis socio-culturais das famílias em análise e conhecendo a relevância da condição social não só nos resultados escolares como no conjunto das práticas e representações dos sujeitos, decidimos controlar o efeito da escolaridade da mãe, limitando aos alunos cuja mãe tem baixa escolaridade (Tabela 4).

Os resultados não se alteram substantivamente, dado que, na quase totalidade dos casos, se mantém a distância e a hierarquia entre os grupos de alunos - a principal diferença dá-se em relação à frequência das reuniões convocadas pela escola: neste caso, as famílias de origem cabo-verdiana vão tanto às reuniões escolares como as que são de origem indiana. Quando se especifica quer o tipo de apoio que recebem como o conteúdo do diálogo sobre a escolaridade, evidenciam-se diferenças dignas de registo.

Comparando com os alunos autóctones, os alunos que vivem em famílias de origem imigrante (indiana ou cabo-verdiana) recebem menos apoio dos pais e, em contrapartida, contam mais com o apoio dos irmãos ou dos explicadores. Destaca-se, igualmente, o recurso das crianças de ascendência indiana a elementos da família alargada, a vizinhos ou a amigos (quando a mãe é pouco escolarizada, 30\% das crianças usam este apoio) e menos aos pais.

Tabela 4: Práticas familiares de apoio à escolaridade (só alunos com mãe até ao $6^{\circ}$ ano)

\begin{tabular}{lccc} 
& Autóctones & $\begin{array}{c}\text { Origem cabo- } \\
\text { verdiana }\end{array}$ & Origem indiana \\
\hline Presença nas reuniões & 90.7 & 88.1 & 87.9 \\
Controlo dos TPC & 89.0 & 89.7 & 94.0 \\
\hline Apoio nas dificuldades & 84.0 & 78.0 & 89.6 \\
$\quad$ Mãe/pai & 57.4 & 40.7 & 37.3 \\
Irmãos & 35.9 & 44.1 & 41.8 \\
Outros (fam., viz., amig.) & 11.8 & 15.3 & 29.9
\end{tabular}




\begin{tabular}{lccc} 
Explicador(a) & 7.2 & 8.5 & 7.5 \\
\hline Diálogo sobre a escola $^{6}$ & 76.4 & 83.1 & 80.3 \\
Aprendizagem & 22.4 & 40.7 & 28.4 \\
Resultados & 19.4 & 23.7 & 38.8 \\
Comportamentos & 16.9 & 22.0 & 11.9 \\
\hline \hline
\end{tabular}

Fonte: Elaboração própria.

Assim, carece de sustentação empírica a ideia de que as mães de origem indiana, por serem predominantemente domésticas, garantiriam um apoio na realização dos trabalhos escolares, vantajoso para o êxito escolar das crianças com esta origem nacional. ${ }^{7}$ Como nos esclareceu em entrevista uma antropóloga que tem realizado um trabalho etnográfico junto de famílias de origem indiana que vivem em Portugal:

Não me lembro propriamente de ter assim nenhuma mãe que chegasse a casa e dissesse "agora senta-te aí e faz os trabalhos." E estar ali com o menino a ensinar de uma maneira... Não me lembro de ter esta imagem. Embora elas dissessem "vai fazer os trabalhos de casa" ou... é preciso material para a escola?", "tens os livros?", "o que é que tens?". "o que é que não tens?". (SUSANA BASTOS, 7/2/2003).

Quando se especifica os temas predominantes no diálogo familiar, verifica-se que enquanto as famílias de origem cabo-verdiana se centram nos aspectos relativos ao processo de aprendizagem, as de origem indiana dão mais relevo aos resultados obtidos (em relação às de origem cabo-verdiana e às famílias autóctones) e menos atenção aos aspectos de ordem comportamental e de regulação do cumprimento global da escolaridade (o que poderá não ser alheio ao cumprimento das regras escolares, por parte os seus descendentes).

Agregando este conjunto de indicadores num índice de apoio à escolaridade por parte das famílias, ${ }^{8}$ verificámos atingirem valores mais elevados as famílias de origem indiana, seguindo-se as autóctones e as de origem cabo-verdiana (a mesma hierarquia que acorre no desempenho escolar). Podemos, ainda, constatar que o apoio da família à escolaridade produz efeitos sobre o desempenho escolar, numa relação directa, ou seja, sempre que o apoio

${ }^{6}$ Trata-se da resposta a uma questão aberta e definiram-se as temáticas do diálogo de acordo com a seguinte classificação: Aprendizagem quando as respostas remetiam para "aulas", "matérias" e "professores"; Resultados nos casos em que se fala de "notas" e "testes"; Comportamentos quando a resposta foi "comportamento", "faltas", "TPC" ou "recados na caderneta".

${ }^{7}$ Foi possível saber que estas mães terão um menor domínio da língua portuguesa escrita do que as de origem cabo-verdiana.

${ }^{8} \mathrm{O}$ índice resulta da soma das respostas dadas às questões. Foi considerado apoio fraco quando os progenitores implementavam uma ou duas destas práticas (não existiam casos em que nenhuma ocorresse), apoio médio quando não ocorre uma delas e apoio forte quando acontecem todas em simultâneo. 
familiar aumenta o sucesso também aumenta, sendo os ganhos particularmente visíveis no caso das famílias de origem cabo-verdiana (figura 1).

Em suma, se, por um lado, no tocante à dinâmica familiar de acompanhamento da escolaridade, os melhores resultados dos alunos de origem indiana poderão relacionar-se com um maior apoio à escolaridade (sustentado por uma base mais alargada de recursos em caso de dificuldades escolares, agregada a uma maior pressão familiar sobre os resultados obtidos) por outro, também se constata que, para semelhante nível de apoio familiar, os resultados dos diferentes grupos mantêm a hierarquia pré-existente e a diferença é igualmente significativa, especialmente quando todos recebem um fraco apoio familiar. Este facto impede-nos de considerar elemento central ou decisivo do desempenho escolar o acompanhamento familiar que os alunos recebem.

Figura 1: Sucesso escolar (\%) segundo o apoio familiar à escolaridade

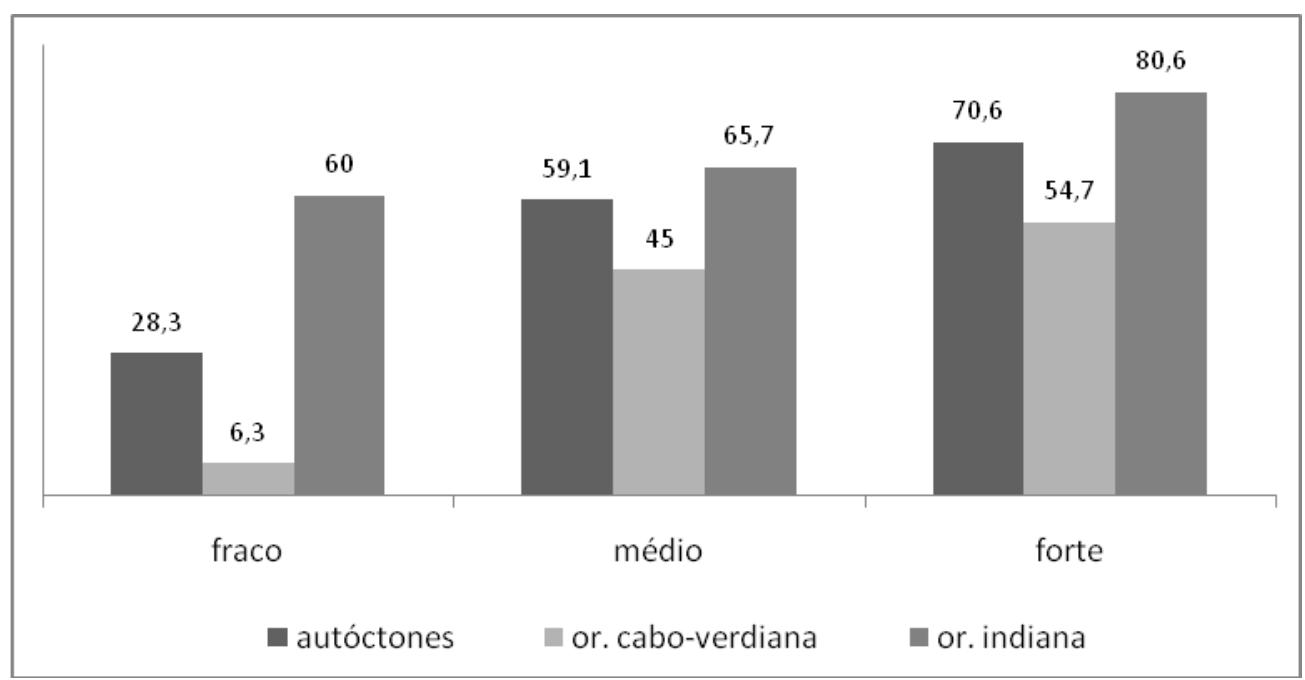

Fonte: Dados da pesquisa.

\section{Aspirações escolares e profissionais}

Além das práticas de apoio á escolaridade dos descendentes, foi realizado um levantamento das aspirações escolares e profissionais das suas famílias. ${ }^{9}$

Em relação às primeiras, revelaram-se bastante elevadas, pois a maioria deseja que os filhos completem o ensino superior (exceto no caso das famílias de origem indiana), e há, um

9 A questão colocada foi a seguinte: “Até quando é que a tua família quer que tu estudes?" 
desinteresse generalizado em cumprir apenas a escolaridade obrigatória ( $9^{\circ}$ ano), sendo transferida essa meta para o final do ensino secundário $\left(12^{\circ}\right.$ ano $)$.

Contudo, estas aspirações variam com a origem nacional das famílias. As crianças de origem indiana, relativamente a qualquer dos outros grupos de crianças, vivem mais frequentemente sem saber qual a meta que os pais desejam que elas atinjam e sofrem uma menor pressão para que obtenham um diploma de ensino superior. Contrariamente, este é o desejo mais forte das famílias de origem cabo-verdiana, atingindo os $75 \%$ quando se trata de raparigas. São sempre mais elevadas as aspirações dos progenitores quando os descendentes são raparigas (em concordância com o maior êxito escolar), mas, mais uma vez, as famílias de origem indiana fazem a excepção à regra: apesar dos seus melhores resultados, desejam que as filhas completem baixos níveis de escolaridade.

Tabela 5: Aspirações escolares da família por origem nacional e sexo do aluno

\begin{tabular}{l|cc|c|cc|c|cc|c}
\hline \multirow{2}{*}{\multicolumn{1}{c|}{ Sexo }} & \multicolumn{3}{c|}{ Autóctones } & \multicolumn{3}{c|}{ Origem cabo-verdiana } & \multicolumn{3}{c|}{ Origem indiana } \\
\cline { 2 - 10 } & $\mathrm{F}$ & $\mathrm{M}$ & Total & $\mathrm{F}$ & $\mathrm{M}$ & Total & $\mathrm{F}$ & $\mathrm{M}$ & Total \\
\hline Até $6^{\circ}$ ano & 3.7 & 9.0 & 6.4 & - & 7.3 & 3.6 & 17.6 & 12.1 & 14.7 \\
Até $9^{\circ}$ ano & - & 0.5 & - & - & 1.8 & 0.9 & 2.0 & 1.7 & 1.8 \\
Até $12^{\circ}$ ano & 11.6 & 13.4 & 12.6 & 5.5 & 10.9 & 8.2 & 13.7 & 15.7 & 14.7 \\
Até universidade & 57.2 & 53.8 & 57.5 & 74.5 & 50.9 & 62.7 & 23.5 & 39.7 & 32.1 \\
Sem indicação & 27.4 & 23.2 & 23.5 & 20.0 & 29.1 & 24.5 & 43.2 & 31.0 & 36.7 \\
\hline \hline
\end{tabular}

Fonte: Elaboração própria.

Quando restringimos a análise às famílias cuja mãe tem baixa escolaridade (Tabela 6), verificamos que, tendencialmente, as aspirações familiares se deslocam ligeiramente para níveis inferiores de escolaridade, aumentam as situações de indefinição quanto à meta a atingir e as famílias de origem indiana afastam-se, ainda mais, das restantes famílias, acentuando-se as suas baixas aspirações escolares: cerca de $20 \%$ coloca como nível mínimo a atingir apenas o $6^{\circ}$ ano de escolaridade, em apenas $25 \%$ das famílias pretende-se que o educando complete um curso de ensino superior (quando essa ambição existe em quase $60 \%$ das famílias de origem cabo-verdiana) e em muitas (quase 40\%) não se indica nenhuma meta escolar obrigatória.

Tabela 6: Aspirações escolares das famílias por origem nacional (aluno com mãe até $6^{\circ}$ ano)

\begin{tabular}{cccc} 
& Autóctones & $\begin{array}{c}\text { Origem cabo- } \\
\text { verdiana }\end{array}$ & Origem indiana \\
\hline Até $6^{\circ}$ ano & 9.7 & 3.4 & 19.4
\end{tabular}




\begin{tabular}{lccc} 
Até $9^{\circ}$ ano & - & 1.7 & 1.5 \\
Até $12^{\circ}$ ano & 16.5 & 10.2 & 17.9 \\
Até universidade & 51.5 & 59.3 & 22.4 \\
Sem indicação & 22.4 & 25.5 & 38.8 \\
\hline
\end{tabular}

Fonte: Elaboração própria.

Este conjunto de diferenciações internas, quando estamos em presença de famílias com perfil social semelhante, remete para a insuficiência dos dados estruturais no esclarecimento das práticas e representações, dando ênfase às dinâmicas familiares, como têm revelado outros estudos (DIOGO, 1998, 2008; KELLERHALS; MONTANDON, 1991; KELLERHALS; TROUTOT, 1987; MONTANDON, 1996; LAHIRE, 1995).

Feito o diagnóstico, somos imediatamente interpelados pela estranheza das aspirações familiares variarem na relação inversa do desempenho escolar. Como interpretar este aparente paradoxo entre o diferencial de (in)sucesso escolar atingido por estas duas populações de alunos e as metas a atingir na escolaridade? Será a maior precaridade das condições de vida (nomeadamente a forte incidência da monoparentalidade), que impulsiona as famílias de origem cabo-verdiana a olharem para os diplomas escolares superiores como a principal (senão a única) saída da situação em que se encontram? E o desejo de cumprimento de uma escolaridade intermédia patente nas famílias de origem indiana estará relacionado com a colocação dos descendentes no mercado de trabalho co-étnico sustentado pelo comércio ou, em outros casos, com a expectativa de prolongarem a condição de trabalhadores independentes?

Os seus depoimentos dão alguma consistência a estas hipóteses.

Eu também quero que ele estude... que faça um curso... o $9^{\circ}$ ano é pouco, quanto mais estudo melhor... tenho-lhe dito: estuda para eu ver se o meu filho fica numa secretária a sujar e outros a limpar o que ele suja... que é o que eu hoje faço [...]. (Ana, natural de Cabo Verde, sem diploma, empregada de limpeza).

- A sua filha tem 13 anos e imagine que aos 15 quer deixar de estudar. Como é que reage?

Eu convencia-a a continuar. Eu falo muito com elas do meu exemplo: [...] olhem, eu estudei até ao $6^{\circ}$, não estudei mais, queria ter uma boa profissão... por exemplo, o meu sonho é ser educadora e sei que para ser educadora tenho que estudar até ao $12^{\circ}$ "; e eu digo-lhes: "vocês têm de estudar que é para terem uma profissão, ter um curso. (Maria natural de Cabo Verde, $9^{\circ}$ ano, auxiliar de creche). 
Ele queria desistir e eu é que não deixei. Ele disse: "mãe vou trabalhar e estudar à noite!" e eu disse: "Não! Enquanto a mãe puder trabalhar, tu estudas! O que eu quero é ver estudos e ver-te com o teu curso!. (Rosa, natural de $\mathrm{S}$. Tomé, $10^{\circ}$ ano, auxiliar de jardim de infância).

Se eles quiserem deixar de estudar depois do $9^{\circ}$ ano, não tem problema... não insisto, mas até ao $9^{\circ}$ ano tem que ser. Com o $9^{\circ}$ ano podem fazer um estágio (em bancário, por ex.) e ficam equivalência ao $12^{\circ}$ ano. (Radica, natural de Moçambique, $6^{\circ}$ ano, empregada de limpeza).

Ele diz que quer estudar até ao $9^{\circ}$ ano e depois vai trabalhar para ajudar. Ele quer ajudar-nos, quer arranjar um bom emprego... tratar da vida dele, tirar a carta, como qualquer pessoa [...]. (Priti, natural de Diu, $5^{\circ}$ inglês, doméstica, $6^{\circ}$ ano).

Ela é que vai decidir, mas já está mentalizada que se tirar uma licenciatura vai ter uma vida melhor... faço-a ver que é melhor. Se eu tivesse uma loja, um empreendimento, se fosse comerciante, se calhar era diferente [...]. (Pradip, natural de Diu, licenciado, dentista).

Quanto às baixas ambições das famílias de origem indiana em relação às suas filhas, uma das mães com esta origem explicou-nos os motivos desta diferenciação de gênero que impede as raparigas de prosseguir os estudos, apesar de manifestarem vontade de o fazer, e que se resumem ao garante de um equilíbrio no mercado matrimonial, suporte da sustentabilidade do casamento; em última instância, está em jogo a própria reprodução cultural.

Júlia (natural de Diu, sem diploma, vendedora por conta própria) tem 3 filhas e um rapaz mais novo: as duas mais velhas completaram o $9^{\circ}$ ano e casaram poucos anos depois e a terceira prosseguiu até ao $12^{\circ}$ ano, que só ficou incompleto por não ter conseguido transitar a uma disciplina. O rapaz, por sua vez, pode (e até é desejável) tirar um curso superior.

\section{E se ele fosse para a universidade não ficava contra ele?}

Não, não. Gostava. É diferente, é rapaz. Nós os indianos, a maior parte das raparigas não estudam muito, quando têm 20 anos, 20 e tal anos, casam. E depois dos 20 e tal anos já custa um bocado procurar, na nossa comunidade. Estudar não quer dizer que não case. Mas é difícil quando tem muitos estudos. Se a nossa filha estudasse muito tínhamos que arranjar um rapaz que estudou também, está a ver... Têm que se dar os dois bem. Quando o marido não estudou e a mulher estudou ela tem aquela coisa...você não estudou, você não é nada. Depois tem ciúmes. [...] Mas porque é que deixou que esta filha mais nova fosse até ao 12. ${ }^{\circ}$ ? Porque ela queria... Outras pronto... Uma quando tinha os 16 anos, um rapaz veio-a pedir, o rapaz era bom e depois quando tinha os 19 anos casou. Essa filha fez o 9..$^{\circ}$ ano, o rapaz já a tinha pedido e o rapaz era bom... Mas a gente falou com ela... também 
não é à força que se casam...não é de qualquer maneira, um vem pedir e damos... A gente vê como é que é o futuro do rapaz, a gente procura saber, como é que é, como é que não é...para entrar para a família... Depois fez o 9. ${ }^{\circ}$...nós também não somos ricos, pertencemos a uma casta mais normal, estuda até tanto, não estuda muito... Mas rapaz é diferente das raparigas... raparigas a gente não deixa muito... Se ele estudar muito à frente não importa. Agora raparigas... se estudam muito já a cabeça fica de outra maneira., fazem aquilo que elas querem... Eu conheço uma menina que está na universidade, os pais falam e ela nem ouve. Ela não liga. Pronto está a fazer bem, está a estudar, mas não está dentro do coiso e mãe e pai sempre ficam... Parece que ela está afastada de nós, está a ver...e a gente tem medo de deixar estudar muito." 10

Quanto às profissões indicadas pelos progenitores como desejáveis, 32\% dos alunos não assinala qualquer indicação (este valor não varia com os subgrupos em análise) e as referências mais frequentes são a de médico, a de desportista (de futebol ou outras modalidades), a de advogado, veterinário, engenheiro ou professor. Conforme os subgrupos, varia a incidência da indicação: a medicina no caso dos alunos de ascendência indiana e a advocacia no caso dos de origem cabo-verdiana. Quanto às diferenças de género, constatamos que as expectativas sobre as profissões mais prestigiadas socialmente recaem sobretudo nas raparigas, aspecto que é comum a todos os grupos em análise.

Em suma, sabemos que toda a investigação tem revelado, de modo consistente, que as famílias dos meios sociais mais desfavorecidos não são demissionárias ${ }^{11}$ e a presente investigação dá-nos a indicação que também não o são as famílias imigradas. Detectamos, à semelhança do que aconteceu com Singly (1997) junto das famílias dos meios populares, a existência de uma lógica obsessiva na relação com a escola, inculcando com eficácia a crença nesta como verdadeiro veículo de integração e mobilidade sociais, sobretudo por parte das famílias de origem cabo-verdiana. Já em estudo anterior (SEABRA, 1999) se tornou saliente a centralidade que as famílias imigradas atribuem à escola no sucesso da sua integração na sociedade de acolhimento, procurando que os filhos na escola sejam submissos no modo de falar e de andar ("não andar com aquele rabito arrebitado") e esperando que a escola dê aos seus filhos o conhecimento da cultura portuguesa, dádiva que lhes é difícil concretizar.

Efectivamente, a análise da informação recolhida neste estudo indica-nos que: i) as famílias imigradas não diferem das famílias autóctones no tocante à relação que estabelecem com a escola e não é legítimo falarmos de uma relação menos investida com a escolaridade,

${ }^{10}$ Este receio de que se deixe de viver "em dois tabuleiros" e se passe a optar por um deles, como seria o caso desta universitária que a entrevistada referiu, evidencia que a "duplicidade" resulta de uma intencionalidade e de uma necessidade que pode deixar de existir, ou seja, é uma opção, entre outras.

${ }^{11}$ Charlot (1997) entende que em vez de demissão se deve falar de sofrimento e impotência. 
dadas as práticas de suporte à escolaridade dos filhos implementadas; ii) estas famílias multiplicam os pontos de apoio à escolaridade envolvendo uma rede considerável de pessoas exteriores ao núcleo familiar (amigos, vizinhos...), especialmente notório no caso das famílias de origem indiana.

Importa, agora, explorar a importância relativa destas diferentes dinâmicas familiares nas trajectórias escolares dos seus filhos. ${ }^{12}$

\section{Relação entre as condições e os processos familiares e o desempenho escolar}

Considerando estas variáveis relativas ao processo vivencial nas famílias e as que enformam a vida familiar e que são nível estrutural - dadas pelas condições sociais realizámos o cálculo da associação entre as diferentes variáveis e o desempenho escolar (dado pelo valor de Eta); deste modo, é possível hierarquizar as variáveis consoante a intensidade da sua relação com os resultados escolares, tanto para a totalidade dos alunos como para cada subgrupo em particular (Tabela 7).

Na totalidade dos alunos, importa salientar, por um lado, a menor associação dos resultados à origem nacional dos alunos e, por outro, a existência de uma relação mais intensa com as condições socioeducativas e socioprofissionais da família, imediatamente seguidas pelo apoio familiar à escolaridade e expectativas escolares.

Esta ordem de relevância das variáveis mantém-se quando isolamos os alunos autóctones mas sofre alterações quando observamos exclusivamente os alunos descendentes de imigrantes. Neste caso, perdem importância relativa as condições familiares, principalmente a escolaridade do pai, e sobressai o relevo das dinâmicas familiares, em especial o acréscimo da relação do desempenho escolar dos alunos de origem cabo-verdiana e o apoio familiar que recebem. Os resultados dos alunos de origem indiana são os menos afetados pelo apoio familiar à escolaridade.

Tabela 7: Associação entre o número de reprovações e as condições e processos familiares*

\begin{tabular}{l|c|ccc}
\hline \hline & $\begin{array}{c}\text { Todos os } \\
\text { alunos }\end{array}$ & Autóctones & $\begin{array}{c}\text { Origem cabo- } \\
\text { verdiana }\end{array}$ & $\begin{array}{c}\text { Origem } \\
\text { indiana }\end{array}$ \\
\hline Classe social familiar & 0,20 & 0,25 & 0,25 & 0,30 \\
Escolaridade mãe & 0,21 & 0,23 & 0,29 & 0,22 \\
Escolaridade pai & 0,23 & 0,32 & 0,19 & 0,09 \\
Origem nacional & 0.14 & - & - & -
\end{tabular}

12 Só se estabeleceu relação com as variáveis integradas no inquérito por questionário a que os alunos responderam, por serem as únicas quantificáveis. 


\begin{tabular}{l|l|lll} 
Apoio familiar à escolaridade & 0,19 & 0,22 & 0,25 & 0,20 \\
Aspirações escolares (da família) & 0,18 & 0,22 & 0,24 & 0,25 \\
\hline \hline
\end{tabular}

Fonte: Elaboração própria.

\section{Conclusões}

Partimos de grupos de alunos com clara diferenciação de resultados escolares, medidos pela trajectória realizada até ao $5 \% 6^{\circ}$ anos e fomos avaliar em que medida os processos familiares de apoio à escolaridade e as ambições dos pais em relação ao nível de escolaridade a atingir apareciam relacionados com essas diferenças de desempenho.

Comparando o contexto familiar dos alunos de origem indiana, grupo de alunos onde é maior o sucesso escolar, com os seus pares de origem cabo-verdiana ou autóctones, concluímos que no caso dos primeiros: i) os seus pais controlam um pouco mais a realização dos trabalhos de casa; ii) conversam menos sobre a escola mas quando o fazem centram-se mais nos aspectos relacionados com a avaliação; iii) lhes proporcionam uma rede mais alargada de apoio às suas dificuldades escolares; iv) têm menores ambições em relação à escolaridade a atingir.

Ao criarmos um índice de apoio familiar à escolaridade, baseados nas práticas de acompanhamento desenvolvidas pelas famílias, foi possível observar que sempre que a intensidade desse apoio aumenta são melhores os resultados escolares, para qualquer dos grupos em análise. No entanto, também verificámos que, para semelhante nível de apoio familiar, o desempenho escolar dos diferentes grupos mantêm a hierarquia pré-existente e a diferença é igualmente significativa, especialmente quando todos recebem um fraco apoio familiar. Este facto torna evidente não ser pertinente concluir pelo efeito decisivo das práticas de apoio familiar à escolaridade sobre os resultados que os alunos obtêm na escola. Assim, podemos afirmar que este apoio contribui para o desempenho escolar e que as duas variáveis variam numa relação directa, mas esse não constitui, de modo algum, uma condição suficiente ao êxito ou fracasso escolares.

\section{REFERÊNCIAS}

BENAVENTE, A. et al. Do outro lado da escola. Lisboa: IED, 1987.

BERTHELOT, J.-M. Le piège scolaire. Paris: PUF, 1983.

CHARLOT, B. Pour le savoir, contre na statégie. In: DUBET, F. (Org.). École, familles - le malentendu. Paris: Ed. Textuel, 1997. p.59-77. 
DIOGO, A. M. Estratégias de famílias e e escolas: composição social e efeitos escola. In: DAYRELL, J. et al. (Org.). Família, escola e juventude: olhares cruzados Brasil-Portugal. Belo Horizonte : Ed. da UFMG, 2012. p.172-194.

DIOGO, A. M. Investimento das famílias na escola: dinâmicas familiares e contexto escolar local. Lisboa: Celta, 2008.

DIOGO, A. M. Famílias e escolaridade: representações parentais da escolaridade, classe social e dinâmica familiar. Lisboa: Colibri, 1998.

DON, D. As escolas e as famílias em Portugal: realidade e perspectivas. Lisboa: Livros Horizonte, 1987.

DUBET, F. École, familles - le malentendu. In: DUBET, F. (Org.). École, familles - le malentendu. Paris : Ed. Textuel, 1997. p.11-41.

FERHAT, L. O.; TERRAIL, J. P. Mobilisations et démobilisationa. In: TERRAIL, J. P. (Org.). L'école en France: crise, pratiques, perspectives. Paris: La Dispute, 2005.

HENRIOT-VAN, Z. L'école et l’espace local. Lyon: Press Universitaires de Lyon, 1990.

KELLERHALS, J.; MONTANDON, C. Les stratégies éducatives des familles: milieu social, dynamique familiale et l'éducation des pré-adolescents. Neuchâtel: Delachaux et Niestlé, 1991.

KELLERHALS, J.; TROUTOT, P. Y. Milieu social et types de familles: une approche interactive. Annales de Vaucresson, Paris, v.26, p.91-108, 1987.

LAHIRE, B. Tableaux de familles: heurs et malheurs scolaires en milieux populaires. Paris: Gallimard-Le Seuil, 1995.

MONTANDON, C. Les relations des parents avec 1'ecole. Lien Social et Potitiques - RIAC, Quebec, v.35, p.63-73, 1996.

MONTANDON, C. L'articulation entre les familles et l'école: sens commun et regard sociologique. In: VINCENT, G. (Org.). L'éducation prisonnière de la forme scolaire? Lyon: PUL, 1994. p.149-171.

QUEIROZ, J.-M. Les familles et l'école. In: SINGLY, F. (Org.). La famille: l'état des savoirs. Paris: La Découverte, 1991. p.201-210.

SANTIAGO, R. A escola representada pelos alunos, pais e professores. Aveiro: Universidade de Aveiro, 1996.

SEABRA, T. Adaptação e adversidade: o desempenho escolar dos alunos de origem indiana e cabo-verdiana no ensino básico. Lisboa: ICS-UL, 2010.

SEABRA, T. Educação nas famílias: etnicidade e classes sociais. Lisboa: IIE, 1999. 
SEBASTIÃO, J. Democratização do ensino, desigualdades sociais e trajectórias escolares. Lisboa: FCG/FCT, 2009.

SINGLY, F. La mobilisation familiale pour le capital scolaire. In: DUBET, F. (Org.). École, familles: le malentendu. Paris: Ed. Textuel, 1997. p.45-58.

VIEIRA, M. M. Educar herdeiros: práticas educativas da classe dominante lisboeta nas últimas décadas. Lisboa: Fundação Calouste Gulbenkian, 2003.

\section{Como referenciar este artigo}

SEABRA, Teresa. Relação das famílias com a escolaridade e sucesso escolar: comparação entre famílias de origem cabo-verdiana, origem indiana e autóctones. Doxa: Rev. Bras. Psicol. Educ., Araraquara, v.19, n.1, p. 163-180, jan./jun. 2017. ISSN: 1413-2060.

Submetido em: 20/04/2017

Aprovado em: 26/05/2017 